\title{
ESTETYKA OBECNOŚCI FENOMENALNEJ
}

Martin Seel, Estetyka obecności fenomenalnej, przeł. K. Krzemieniowa, Universitas, Kraków 2008.

Czym jest estetyka? Jaka jest jej relacja do filozofii sztuki? Czym różni się percepcja estetyczna od zwykłej percepcji? Jak skoncentrowana na odbiorze zmysłowym teoria estetyczna może objąć fenomen zintelektualizowanej, antyestetycznej sztuki współczesnej? Odpowiedzi na te pytania formułuje niemiecki filozof Martin Seel w przetłumaczonej ostatnio na język polski książce Estetyka obecności fenomenalnej.

Swą teorię estetyczną autor przedstawia przede wszystkim w stanowiącym ponad połowę publikacji obszernym tekście tytułowym. Podstawowa kategoria jego koncepcji to „zjawisko” (die Erscheinung) definiowane jako to, co poznawalne w medium zmysłów (w odróżnieniu od tego, co zmysłowo poznawane). W perspektywie przedmiotowej zjawiskiem jest to, co dostępne zmysłom, innymi słowy: zmysłowa własność przedmiotu. Zespół zjawisk przedmiotu, czyli całość tego, co możliwe w nim do rozróżnienia za pomocą zmysłów, nazywa Seel zmysłowym ukonstytuowaniem przedmiotu (sinnliche Verfassung). Podkreśla przy tym, że przedmiot jako taki nie jest redukowalny do swych zjawisk, gdyż oprócz nich posiada jeszcze własności nieobserwowalne zmysłowo (np. skład chemiczny czy określony układ atomów). Zjawisko nie jest dla Seela tożsame z pozorem, a więc z subiektywnym wrażeniem. Posiada ono obiektywny byt w tym sensie, że jest niezależne od konkretnych aktów postrzegania, jakkolwiek nie jest niezależne od możliwości postrzegania w ogóle. Doświadczenie zjawiska może według Seela przebiegać na dwa różne pod względem zogniskowania sposoby. Pierwszy z nich zachodzi wówczas, gdy zjawisko zostaje opisane za pomocą pojęć, a więc następu- 
je przypisanie przedmiotowi bycia takim a nie innym w sądzie (określenie tzw. bycia faktycznego przedmiotu - Sosein). Drugi sposób natomiast - estetyczny - zachodzi, gdy następuje skoncentrowanie się na byciu tu i oto zjawiska, na samym procesie jego jawienia się (das Erscheinen) - synestetycznego ukazywania w konkretnym miejscu i czasie. Jak pisze Seel, w postrzeganiu estetycznym uprzytamniamy sobie dany przedmiot w procesie jego jawienia się. Cechą charakterystyczną tego podejścia jest skoncentrowanie na jakościowych aspektach zjawiska (np. widoku nieba, nasyceniu dźwięku, atmosferze miejsca, teksturze materiału, zapachu jedzenia), jakkolwiek $\mathrm{w}$ ich aspekcie bycia danymi w takiej a nie innej wyznaczonej przez konkretne miejsce i czas postaci. Ujmowanie bycia faktycznego ma według Seela charakter aspektowy, czyli dokonuje się zawsze pod jakimś kątem, z określonej teoretycznej lub praktycznej perspektywy (przedmiot postrzegany jest jako taki a taki, na przykład piłka jako należąca do konkretnej osoby). Z kolei w wypadku jawienia się nie następuje ograniczenie się do wybranego aspektu przedmiotu, lecz postrzeganie różnych aspektów danego w tym oto miejscu i czasie przedmiotu. Seel przywołuje w tym kontekście Kantowską koncepcję gry, ale w przeciwieństwie do Kanta, mającego na myśli przede wszystkim grę władz poznawczych, akcentuje jej aspekt przedmiotowy: w postrzeganiu estetycznym dostrzegamy relacje i stosunki poszczególnych aspektów do siebie, ich rodzące się w danym miejscu i czasie współgranie:

Dla tego rodzaju patrzenia ważne są kontrasty, interferencje i przejścia, które drwią sobie z każdego opisu, ponieważ dane są tylko w równoczesności i często tylko przez mgnienie w jakichś konkretnych momentach. Odblask światła na powierzchni piłki i pojaśnienie - poruszanych przez wiatr - wierzchołków traw będą ciągle mniej lub bardziej się różnić od siebie, mniej lub bardziej ze sobą harmonizować, pozostawać ze sobą w mniej lub bardziej widocznym napięciu. W ten sposób postrzegany estetycznie przedmiot znajduje się zawsze w stanie przejściowym. W tym stanie nic nie jest po prostu tym czym jest, ale również każda rzecz jawi się w świetle stosunków, w jakich pozostaje z innymi jakościami zmysłowymi, stosunków, które ze swej strony ulegają zmianie z każdą zmianą poszczególnych zjawisk (s. 36).

Odbiorca dostrzega wówczas bogactwo niuansów zjawiska decydujących o niemożności jego pełnego pojęciowego scharakteryzowania w danym momencie. Jako że nie następuje podporządkowanie przedmiotu określonemu pojęciu, przedmiot jest wówczas dany w swej fenomenalnej indywidualności (szczegółowości). Nie oznacza to jednak, że postrzeganie estetyczne jest poznawczo uprzywilejowane. Jak podkreśla autor, doświadczenie obecności fenomenalnej również dokonuje się z określonej - choćby pozycją zajmowaną przez ciało doświadczającego podmiotu - perspektywy. 
Tak ujęte postrzeganie estetyczne - jako specyficzna modyfikacja zwykłego postrzegania - nie jest obszarem ostro oddzielonej od innych aktywności, lecz jedną z wielu współistniejących możliwości oferowanych przez praktykę życiową. Warunkiem realizacji tej możliwości jest według Seela zmiana nastawienia, polegająca na zdystansowaniu się od celów teoretycznych i praktycznych (mogą one być obecne, ale nie na pierwszym planie).

W dalszej części tekstu Seel konstruuje zarys swoistej fenomenologii estetycznego jawienia się. Wyróżnia bowiem trzy wymiary postrzegania estetycznego: jawienie się proste, atmosferyczne oraz artystyczne. W pierwszym wymiarze odbiorca ogranicza się do samego zmysłowego uobecnienia sobie przedmiotu w grze jego zjawisk, nie zastanawiając się nad tym, czy cokolwiek im w rzeczywistości odpowiada czy nie. Przedmiot uobecnia się w taki sposób, że czasowo zawieszone zostaje obdarzanie go dyskursywnymi sensami. Druga możliwość polega na uchwyceniu egzystencjalnego znaczenia przedmiotu (co jest uwarunkowane uprzednią wiedzą podmiotu), tego, że nadaje on swemu otoczeniu charakter atmosfery - znaku wydarzeń przeszłych bądź możliwych. Moment teraźniejszy zostaje tu odniesiony do momentów przeszłych lub przyszłych, miejsce obecne - do miejsc innych. Zarówno jawienie proste, jak i atmosferyczne może wystąpić w wypadku obiektów nieposiadających statusu obiektów artystycznych. Seel przeciwstawia się w ten sposób Heglowskiemu zrównaniu estetyki z filozofią sztuki. Ostatni wyróżniony przez niego rodzaj doświadczenia estetycznego to jawienie się artystyczne. Jego przedmioty są przedstawieniami czy prezentacjami konstelacyjnymi (konstellative Darbietung): pozwalają doświadczyć danej treści za pomocą szczególnego (niemożliwego do zastąpienia) zestawienia (konstelacji) postrzegalnych zmysłowo materiałów. Zmysłowe medium umożliwia w tym wypadku wielokrotne jawienie się. I tak na przykład abstrakcyjny obraz Barnetta Newmana Who's Afraid of Red, Yellow and Blue $I V \mathrm{w}$ modusie jawienia prostego ukazuje układ barwnych plam o zróżnicowanej intensywności i przestrzenności; w modusie jawienia atmosferycznego akcentuje fragment przestrzeni, w której się znajduje, a w modusie jawienia artystycznego dostrzega się jego dialog z innymi dziełami sztuki, sprzeciw wobec malarstwa dekoratywnej, wyważonej formy. Granice między tymi sposobami są płynne, przy czym wiele przedmiotów można postrzegać na więcej niż jeden z nich. Przedmiot może być ponadto tak zbudowany, że sposoby te mogą pozostawać ze sobą w napięciu.

Warunek posiadania przez sztukę tak zdefiniowanego wymiaru zmysłowego zdaje się pozostawać w sprzeczności z faktem istnienia dzieł sztuki nieróżniących się wyglądem od przedmiotów codziennego użytku, dzieł, w których wymiar zmysłowy jest mało istotny. Takim przed- 
miotem jest np. metalowa łopata do zgarniania śniegu M. Duchampa (In Advance of the Broken Arm, 1915). Fakt ten dat innemu teoretykowi sztuki Arthurowi Danto asumpt do stwierdzenia, że zakresy słów „estetyczne” i „artystyczne” nie pokrywają się - o artystyczności obiektu nie decyduje fakt posiadania przezeń wartościowego estetycznie wymiaru, lecz fakt bycia ucieleśnieniem niezmysłowej idei. Seel sprzeciwia się tej konkluzji, wskazując, że zmysłowa identyczność obiektów nie pociąga za sobą identyczności generowanego przez nie doświadczenia estetycznego: wszak, jak przekonująco pokazuje skonstruowana przez Seela teoria, jeden i ten sam obiekt może jawić się estetycznie nawet na trzy różne sposoby w zależności od nastawienia odbiorcy. Nawet jeśli przedmiot zdaje się w ogóle nie umożliwiać żadnego modusu postrzegania estetycznego (jak np. wspomniana łopata Duchampa), to i tak wymiar estetyczny uobecnia się w jego doświadczeniu - jako element niespełnionego oczekiwania odbiorcy na akt jawienia się. Obiekt Duchampa jest częścią sytuacji, która generuje oczekiwanie estetyczności (łopata znajduje się w „świątyni” jawienia się, czyli w muzeum czy galerii), a zarazem powoduje, że nie zostaje ono spełnione (gdyż przedmiot nie dostarcza doznań estetycznych - ani prostego jawienia się ani jawienia się atmosferycznego ani artystycznego). Kontekst pojawienia się przedmiotu wywołuje u odbiorcy nastawienie estetyczne, które jednakże nie jest w stanie się zrealizować.

Pozostałe teksty tomu ukazują relację między teorią Seela a innymi teoriami estetycznymi (Niecierpliwa bistoria nowszej estetyki - co ciekawe prawie brak tu odniesień do tradycji fenomenologicznej, która na tle innych kierunków myśli filozoficznej wyróżniała się ekspozycją tak hołubionego przez autora pojęcia obecności), względnie - doprecyzowują tezy tekstu głównego poprzez odniesienie ich do różnych gatunków sztuki: malarstwa, filmu, muzyki i literatury. Wyróżnia się tu przede wszystkim tekst na temat skrajnych form jawienia się, w których dzieło sztuki jawi się jako zaaranżowana przez artystę amorficzna rzeczywistość (tzw. szum - Flimmern). Seel, operując licznymi przykładami, wskazuje na różne postaci i znaczenia artystycznego „szumu”: od językowego zgiełku powieści E. Jelinek po teatr P. Bausch, w którym tancerze to wykonuja działania niedające się zebrać w spójną całość, to całkowicie minimalizują swe działania tak, że dojmujące staje się wrażenie niedostatku wydarzeń (skrajnym przypadkiem tego ostatniego jest utwór J. Cage'a 4.33, w którym pianista zasiada do fortepianu, ale niczego nie gra).

Również tekst 13 tez na temat obrazu zasługuje na uwagę, jakkolwiek nie ze względu na banalną tezę końcową („Obrazy nie mogą zająć miejsca tego, co rzeczywiste"; choć być może dla niektórych miłośników symulakrycznego katastrofizmu Baudrillarda jest to odkrycie), co raczej ze względu na próbę połączenia fenomenologii i semiotyki 
w teorii obrazu. Do specyfiki zmysłowego uobecniania się obrazu uwydatnianego przez fenomenologię należy tzw. różnica ikoniczna (termin wprowadzony przez G. Boehma) - obecność w doświadczeniu obrazu zarówno tego, co obraz przedstawia, jak i środków, za pomocą których to przedstawianie się dokonuje. Obraz nie tylko zmysłowo prezentuje coś na swej powierzchni (kolory i formy, które w wypadku obrazów nieabstrakcyjnych układają się w przedmioty - „co”), ale również zmysłowo prezentuje samo owo prezentowanie (,jak"). W obu wypadkach mamy według Seela do czynienia z relacją znakową, przy czym w drugim z nich następuje samoodniesienie:

Obraz zawiera nie tylko określone zjawiska (koloru i formy), on się odnosi do swych wewnętrznych odniesień. Dopiero dzięki temu odniesieniu do własnego jawienia staje się obrazem. Dlatego wypada powiedzieć: obiekt wizualny staje się obrazem wtedy, kiedy staje się znakiem tego, co zachodzi na jego powierzchni. Obiekt wizualny staje się obrazem wtedy, kiedy jego odbiorca ujmuje go jako znak tego, co się na nim jawi (s. 213).

Zaproponowana przez Martina Seela teoria estetyczna wydaje się ze wszech miar interesująca, jakkolwiek w kilku miejscach kontrowersyjna. Wątpliwości budzi przede wszystkim jego kategoryczne obstawanie przy estetyczności jako wyróżniku sztuki. Dopatrywanie się przez Seela znamion estetyczności w obiektach J. Kosutha (jak wiemy przeciwnika estetyczności w sztuce, który próbował tejże estetyczności za wszelką cenę uniknąć) wydaje się uzasadnione (szczególnie w kontekście ostatnich wypowiedzi artystów ruchu konceptualnego, w których dystansują się oni od prób zastąpienia przedmiotu ideą, a więc od prób wyrugowania estetyki ze sztuki). Niemniej ujęcie łopaty Duchampa jako przedmiotu, który jest estetyczny poprzez sam fakt odmowy estetyczności (Seel pisze, że w tym wypadku jawienie się artystyczne jest puentą), wydaje się jeśli nie sofistyczną akrobacją - to co najmniej nadużyciem (przypomina ratowanie formalizmu w sztuce przez uznanie, że bezforemność również jest rodzajem formy). Seel pada tu niestety ofiarą swego estetycznego absolutyzmu. Żeby uratować swą koncepcję musiałby zakwalifikować łopatę jako obiekt jawienia się artystycznego (a więc takiego, w wypadku którego występuje prezentacja konstelacyjna), co jednak nie wydaje się możliwe: jeśli przyjmiemy, że celem Duchampa było skonstruowanie obiektu niepozwalającego na realizację estetycznego nastawienia, to w miejscu łopaty mógłby znaleźć się dowolny inny przedmiot. Następna kwestia rodząca wątpliwości to ciągłe obstawanie Seela przy obiektywności zjawiska i procesów jego jawienia się. Autor zupełnie pomija fakt historycznego uwarunkowania procesów odbioru sztuki. Również Kantowski prymat bezinteresowności postawy estetycznej, zdystansowania wobec celów teoretycznych i praktycznych, domaga się wyjaśnień: wy- 
daje się, że istnieją obiekty, których jawienie się może zostać zakłócone, gdy nie zostają spełnione pewne praktyczne funkcje - np. dzieła architektury. Niewątpliwą zaletą książki Seela jest natomiast bogactwo przykładów wskazujące na rozbudowaną - nieograniczającą się do jednego gatunku sztuki - estetyczną wrażliwość autora. Autor umiejętnie łączy rozważania natury ogólnej z rozważaniami natury szczegółowej, zgodnie zresztą z Heglowskim credo umieszczonym na początku książki. Niestety lektura jego tekstów jest utrudniona ze względu na obecne w nich liczne powtórzenia oraz używanie niejasno zdefiniowanych terminów o bogatej tradycji filozoficznej, powodującej, że relacje między nimi nie zawsze są zrozumiałe (np. jawienie się/uobecnianie, postrzeganie jako/ postrzeganie że, prezentacja/reprezentacja/odniesienie). Zadania zrozumienia teorii Seela nie ułatwia polskie tłumaczenie, którego jakość pozostawia wiele do życzenia: i tak na przykład mamy „dystynktywność" tam, gdzie powinna być „wyraźność” (Distinktheit, s. 6), „szczególne” zamiast „szczegółowe” (das Besondere, s. 7, 28), „transparencję” zamiast „nieprzejrzystości” (Intransparenz, s. 24 - sens tłumaczenia dokładnie odwrotny od właściwego!), „gnuśność” zamiast „bezwładności” (Traegheit, s. 221), „pryncypialnie” zamiast „Zasadniczo” (prinzipiell, s. 53), „faseta” zamiast „aspekt” (Facette, s. 114), by wymienić tylko pierwsze $\mathrm{z}$ brzegu przykłady. Ponadto $\mathrm{w}$ wielu miejscach tekstu napotykamy wyrażenia zwyczajnie źle brzmiące. Mowa jest np. o „określonych aspektach określających” (s. 37), „wdzieraniu się plam barwnych poza płaszczyznę obrazu” (s. 21), „doznającym obecności zmyśle” (s. 108), czy „nigdy niebywałych tworach” (s. 89). W niektórych miejscach tekst został przetłumaczony tak, że bez odwołania do oryginału jest niezrozumiały, np. angielskie zdanie z tekstu A. Danto „Artworks and real things cannot be told apart by visual inspection alone” („Dzieła sztuki i realne przedmioty nie mogą być odróżniane od siebie wyłącznie na podstawie analizy wizualnej”) przetłumaczono jako „Dzieła sztuki i realne przedmioty nie mogą być przez wizualny ogląd przekazywane osobno" (s. 247). Pojawiają się też źle przetłumaczone zaimki, jak np. w zdaniu o teatrze Piny Bausch, w którym mowa o niewykorzystywanej strukturze, choć w oryginale chodzi o strukturyzujące postrzeganie (s. 180). Wszystko to sprawia, że lektura tekstu Seela wymaga od czytelnika sporej cierpliwości. Mam nadzieję, że nikomu jej nie zabraknie. 